Positions de la comète $1888 \ldots$ (Brooks Août 7)

mesurées à l'observatoire de Besançon par M. Gruey.

(Note de M. Gruey.)

\begin{tabular}{|c|c|c|c|c|c|c|c|c|c|c|}
\hline 1888 & T. m. Bes. & $\Delta \mathrm{AR}$. & $\triangle \mathrm{DP}$. & Cp. & AR. app. & $\log p .4$ & DP. app. & $\log p .4$ & Red.ad l. app. & * \\
\hline $\begin{array}{r}\text { Août } 9 \\
\text { I } \\
\text { I I }\end{array}$ & $\begin{array}{rrr}10^{\mathrm{h}} & 5^{\mathrm{m}} & 40^{\mathrm{s}} \\
\text { 10 } & 0 & 55 \\
9 & 22 & 35\end{array}$ & $\begin{array}{l}-3^{\mathrm{m}} 3^{8 \mathrm{~s}} 44 \\
+35^{6.18} \\
-24^{6.4}\end{array}$ & 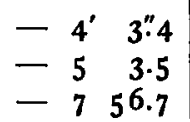 & $\begin{array}{r}9.18 \\
12.24 \\
12.32\end{array}$ & 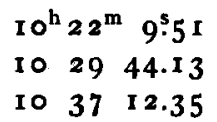 & $\begin{array}{l}9.619 \\
9.621 \\
9.68 z\end{array}$ & $\begin{array}{rrrr}45^{\circ} & 10^{\prime} & 27 & 7.9 \\
45 & 9 & 28.0 \\
45 & 10 & 21.2\end{array}$ & $\begin{array}{l}0.873 n \\
0.872 n \\
0.834 n\end{array}$ & $\begin{array}{l}-0.79-1.4 \\
-0.79-1.2 \\
-0.78-1.9\end{array}$ & $\begin{array}{l}\text { I } \\
\mathbf{I} \\
2\end{array}$ \\
\hline
\end{tabular}

Positions moyennes des étoiles de comparaison pou r r888.o.

\begin{tabular}{|c|c|c|c|c|}
\hline * & Gr. & AR. I 888.0 & DP. I 888.0 & Autorité \\
\hline $\begin{array}{l}\text { I } \\
2\end{array}$ & $\begin{array}{c}7 \\
8.5\end{array}$ & $\begin{array}{l}x 0^{\mathrm{h}} 25^{\mathrm{m}} 4^{8} \cdot 74 \\
103959.54\end{array}$ & $\begin{array}{lll}45^{\circ} & 14^{\prime} & 3^{2} . " 7 \\
45 & 18 & 19.8\end{array}$ & $\begin{array}{l}W_{2} 10^{\mathrm{h}} .470 \\
\text { Lal. } 20726\end{array}$ \\
\hline
\end{tabular}

L. F. Gruey.

\title{
Ephemeride des Faye'schen Cometen (1888 ...)
}

für $\mathbf{I}^{\text {h }}$ M. Z. Berlin.

Die nachfolgende Ephemeride ist aus meinen Rechnungen, betreffend die Wiederkehr des Faye'schen Cometen im Jahre 1888 (vergl. A. N. 2849) unter der Voraussetzung interpolirt worden, dass der Durchgang durch das Perihel 2.60 Tage später, als die Möller'schen Elemente ergeben, stattfindet. Die bis jetzt hier bekannt gewordenen Beobachtungen Aug. 9-I7 Nizza werden unter dieser Annahme nahe dargestellt und es ist daher zu hoffen, dass die Ephemeride für die nächste Zeit den Bedürfnissen der Beobachter genügen wird. Die Helligkeit vom 9. August liegt den Helligkeitsangaben zu Grunde.

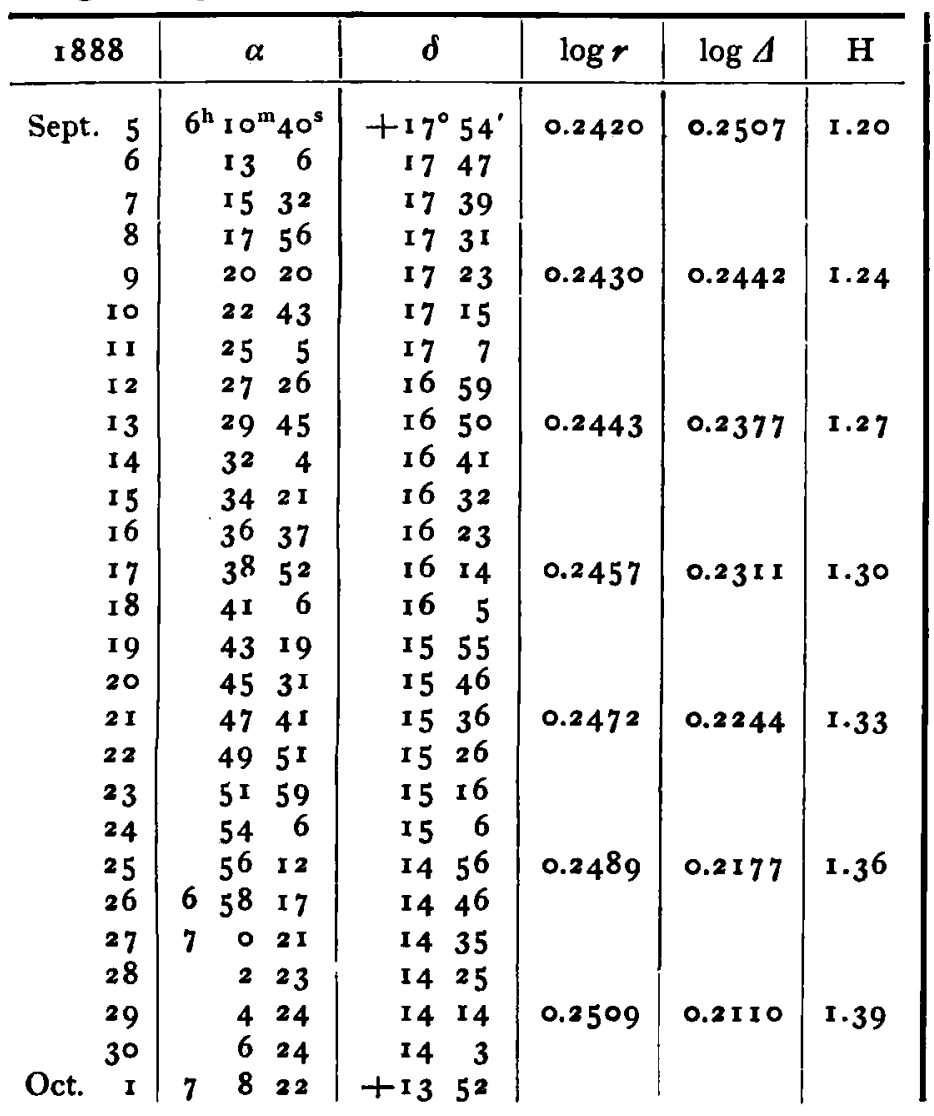

\begin{tabular}{|c|c|c|c|c|c|c|c|c|}
\hline I 888 & \multicolumn{3}{|c|}{$\alpha$} & \multicolumn{2}{|c|}{$\delta$} & $\log r$ & $\log A$ & $\mathbf{H}$ \\
\hline Oct. & $7^{\text {h }}$ & $8^{n}$ & $\mathrm{~m}_{22} \mathrm{~s}^{\mathrm{s}}$ & +13 & ${ }^{\circ} 52^{\prime}$ & & & \\
\hline & & 10 & 19 & I 3 & $4 I$ & & & \\
\hline & & I 2 & $\times 4$ & 13 & 30 & 0.2530 & 0.2042 & 1.42 \\
\hline & & I 4 & 8 & 13 & 19 & & & \\
\hline & & 16 & $\circ$ & 13 & 7 & & & \\
\hline 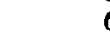 & & 17 & $5 \mathrm{I}$ & I 2 & $5^{6}$ & & & \\
\hline : & & I 9 & $4 I$ & $\mathbf{I} 2$ & 44 & 0.2553 & 0.1973 & I. 45 \\
\hline 8 & & 21 & 29 & I 2 & 33 & & & \\
\hline S & & 23 & 15 & 12 & 21 & & & \\
\hline IC & & 25 & 0 & I 2 & 10 & & & \\
\hline I & & 26 & 43 & I I & $5^{8}$ & 0.2577 & 0.1904 & $1.4^{8}$ \\
\hline I & & 28 & 25 & I I & 47 & & & \\
\hline $\mathbf{I}$ & & 30 & 5 & $\mathbf{x} \mathbf{I}$ & 35 & & & \\
\hline $\mathbf{I}$ & & 3 I & 43 & I I & 23 & & & \\
\hline $\mathbf{I}$ & & 33 & 20 & I I & II & 0.2603 & 0.1835 & $\mathrm{I} .5 \mathrm{I}$ \\
\hline I & & 34 & 55 & ro & 59 & & & \\
\hline 17 & & 36 & 29 & 10 & 47 & & & \\
\hline 18 & & $3^{8}$ & I & ro & 35 & & & \\
\hline IS & & 39 & 32 & Io & 23 & $0.263 x$ & 0.1765 & I. 54 \\
\hline 20 & & 41 & I & Io & I I & & & \\
\hline 21 & & 42 & 28 & & 59 & & & \\
\hline 22 & & 43 & 53 & 9 & 47 & & & \\
\hline 23 & & 45 & 17 & 9 & 35 & 0.2660 & 0.1694 & 1.57 \\
\hline 24 & & 46 & 39 & 9 & 23 & & & \\
\hline 25 & & 47 & 59 & 9 & I I & & & \\
\hline 26 & & 49 & I 7 & 8 & 59 & & & \\
\hline 27 & 7 & 50 & 34 & +8 & 47 & 0.2690 & 0.1623 & 1.60 \\
\hline
\end{tabular}

Kiel 1888 Sept. 5 .

H. Kreutz. 